\title{
Public Domesticity: The Beach as a Model
}

\author{
SILVIA COLMENARES \\ Universidad Politécnica de Madrid
}

The temporary and collective appropriation of public spaces has become a way of pointing out the failure of their institutional management. But through the whole system of locally produced opportunities of engagement, a tendency to execute this appropriation by the performance of domestic scenes can be identified. Therefore, the aim of this paper is to describe this growing tendency to reclaim what is public by showing its capacity to be used as private, and among those, the 'beach' will be described as a model. Being the perfect incarnation of the idea of human fellowship in the open air, the beach regulates itself through its very un-programmed usage. This might be the reason why its genuine conditions have been tentatively replicated at the core of some highly urban scenarios. However, this experience oriented design examples seem to be just a rehearsal of what a real beach should be. Relying on the physical properties of the sand and the colourful atrezzo accompanying sunbaths, they fundamentally fail to engage the radicalness of the beach concept. If the topical image of relaxed individuals is superseded, bydefault distribution of space, access control, cleansing and security issues come to the fore. At a time when it is no more 'under the pavement', the beach can still gear the debate about public space in our cities.

\section{INTRODUCTION}

The postmodern vision of interlocking contradictory caTegories has affected the public/private dichotomy, perhaps more than any other. With the loss of faith in the collective that came by the hand of the end of WWII, the individual became more and more ubiquitous while at the same time more homogeneous in the new globalized context.

The blurring of the identification of the private with the interior has run parallel to the increasing development of information technologies. Today, there is not such a thing that can be defined as private in its own right, because it depends on the condition that each individual gives to it. Domestic attitudes can happen everywhere. They no longer need any physical filter to be defined as intimate.

On its part, the idea of 'public space' has become more and more intangible, - or less and less spatial - tending to be conceptually identified either with that of 'public domain', that is, a kind of publicness basically defined by accessibility and property; or with that of 'public realm', understood as a regime of collective inter-action and an arena for the inter-visibility of actors. Therefore, this shift has progressively pushed the meaning of public space from that of a physical space towards a legal or discursive space, while at the same time our shared urban places have experimented a great pressure to serve as mere support for private commercial interests.

Amid this scenario, the spontaneous or temporary appropriation of public spaces by common people has become a way of pointing out the failure of their institutional management. This kind of citizen involvement in the collective construction of public meaning - that flourished for the first time during the sixties as 'action urbanism'-received several names through the following decades: 'tactical urbanism', 'guerrilla urbanism', 'pop-up urbanism', 'hand-made urbanism' or even 'ecological urbanism'... Through the whole system of locally produced opportunities of individual engagement with publicness, a growing tendency to execute this appropriation by the performance of domestic scenes can be identified.

So here is what we have: the private going public by means of the exposure of intimacy and the public used as private in a continuous rehearsal of domestic scenes. This paper will explore the beach as a model where all these contradictory practices are made evident, presenting itself as a place where the knowledge developed by spatial disciplines could and should be intersected with anthropological and social behavior considerations.

\section{THE BEACH IDEA}

There is a psychological effect associated to the image of a beach that automatically transports us to a relaxed time, a wishful vacation state of mind. Even if we are fully aware that reality is not always as pictured at the cover of travel agencies booklets, -or a simple google search-, our unconscious persistently brings an idealized image of ourselves laying on a deck chair under a moderate sun and a gentle breeze. The shore is undoubtedly a space of desire. A paradise on earth. However, I would like to consider here not the 'ideal beach' but the beach as a spatial idea, as a concept.

The homogeneous composition of the sanded surface speaks of a potentially endless space with no fixed shape or size. Not by chance, in their famous distinction between the smooth and the striated, Gilles Deleuze and Felix Guattari refer to the desert, along with the sea, as paradigmatic cases of the first one.

Following the authors, a smooth space is defined as a vectorial field, a nonmetric multiplicity of positions. It does not 


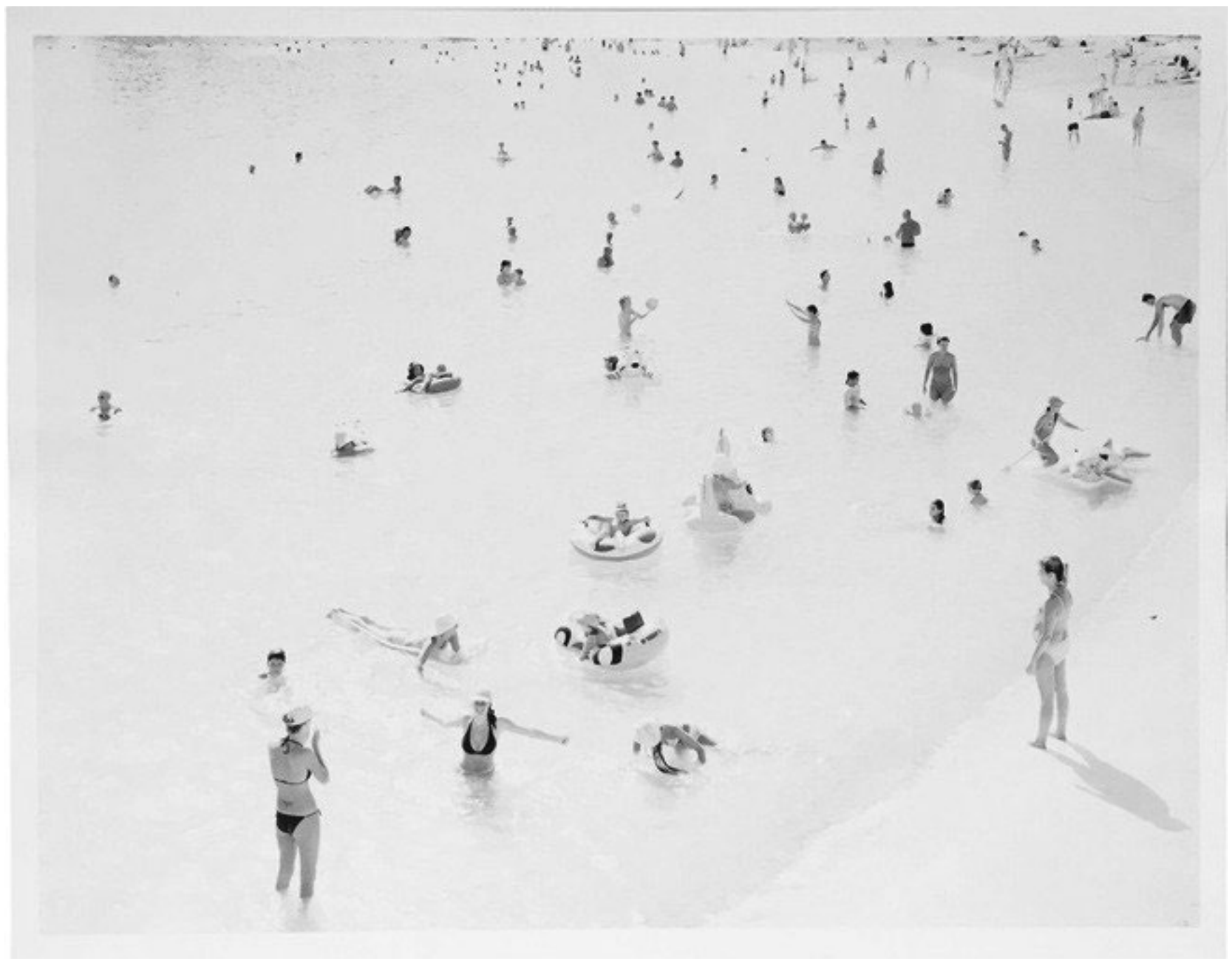

Figure 1: Massimo Vitali. Knokke Polyptych, 2002. Source: www.massimovitali.com

measure, the smooth can only distribute. As they explain, "the smooth and the striated are distinguished first of all by an inverse relation to the point and the line (in the case of the striated, the line is between two points, while in the smooth, the point is between two lines)"1. This passage exemplifies very well the spatial conditions at stake in any beach. Considering the fact that it is limited by two conceptually parallel lines, that of the water edge and that of the contact with the territory, any possible position within those is just a point, a spot with no Cartesian coordinates, because there is no zero-zero origin.

The fundamentally un-programmed condition of the beach reinforces its potentiality as scenario of free human activity. Of course, some functional goals as sun exposure and bathing are behind its use, but what is really consumed in beaches is time itself. The beach is a machine where personal leisure time is transformed into experiential memories. Beach time elapses in the absence of a fixed plan.
This might also be the reason why they are under-designed spaces. Their temporary occupation does not require a great infrastructure. For those who find the soft adaptable microtopography of the sand too poor for their comfort standards, a simple towel will serve as a perfect dispositive of land appropriation. Being a nomad for a day, each individual performs his or her own 'carpet show' in a play where everyone becomes an actor as well as part of the public.

Through the continuous construction of one's own private space, the collectively shared setting of the beach is once and again transformed from sunrise to sunset. Its shape at each moment is that of the very bodies that occupy it and the way they are arranged at the field. And one of the properties of this field is that density, no matter if it is high or low, is always a constant. Proximity between bodies has its unspoken rules, so people tend to distribute at equivalent distances, just as herds or flocks do. Images of the beach always transmit a certain sense of texture. 


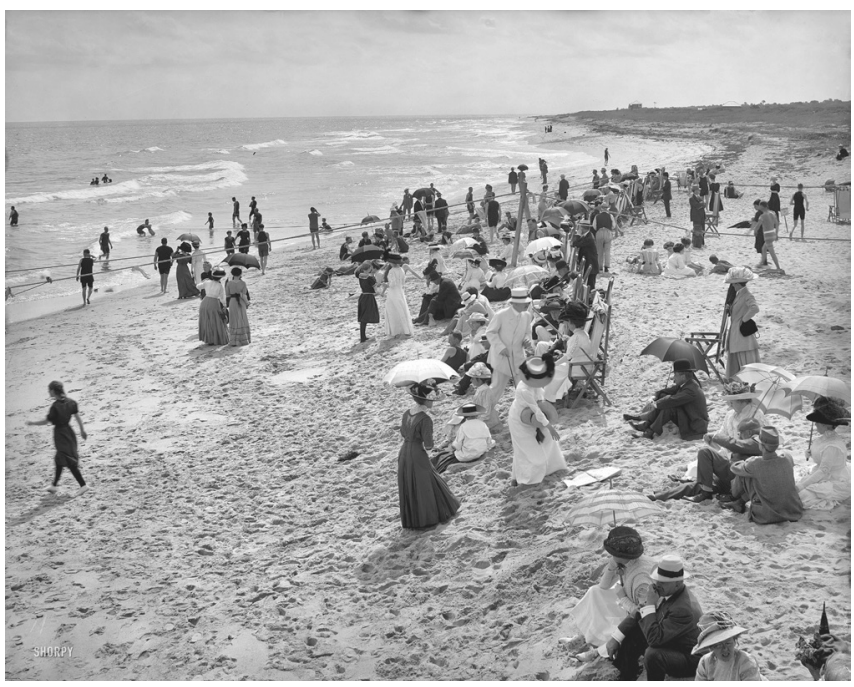

Figure 2: Bathing at west Palm Beach, Florida circa 1910. Source: Detroit Publishing Company

However, this does not mean that beaches have no limits. No matter how un-programmed or under-designed, they are always oriented spaces, with front and back and a variable width running parallel to the tidal line.

\section{A SOCIAL APPROACH TO NATURE}

Through the course of history, the boundary between earth and ocean, between the known and the uncertain, always inspired fear to men. Contact with nature will only become desirable in relation to health issues during the second half of the eighteen Century, when European elites began seeking the curative qualities of fresh air, exercise and sea bathing. According to the French historian Alain Corbin ${ }^{2}$, in the romantic sensibility captured in the new pictorial genre of the seascape, the beach held the promise of self-discovery.The words that Honoré de Balzac uses to describe it in one of his novels might well illustrate this sense of newness in the encounter with nature: "It is large, without being wild; it is immense, without being deserted; it is monotone, without being tiring" 3 .

Paradoxically enough, the birth of the beach as a social practice related to nature came by the hand of the rising of urban and industrial society. As a counterpart of modern life, the beach represented the possibility of escaping the city. The fashion for seaside holidays promoted the idyllic social portrait of shoredwelling people and their lifestyle, turning the fisherman scenes into a spectacle for the urban cultivated men.

But definitely, the quest for the exotic, the almost ethnographical interest for 'the other' that was at the roots of the first beach-users, started to change during the 19th Century and turned out into a quite hedonistic approach to the pleasures provided by the direct interaction with the elements. Even in a highly coded society, the need to interact with sun and water gave birth to unprecedented ways of standing and posturing, sitting or lying on the sand.

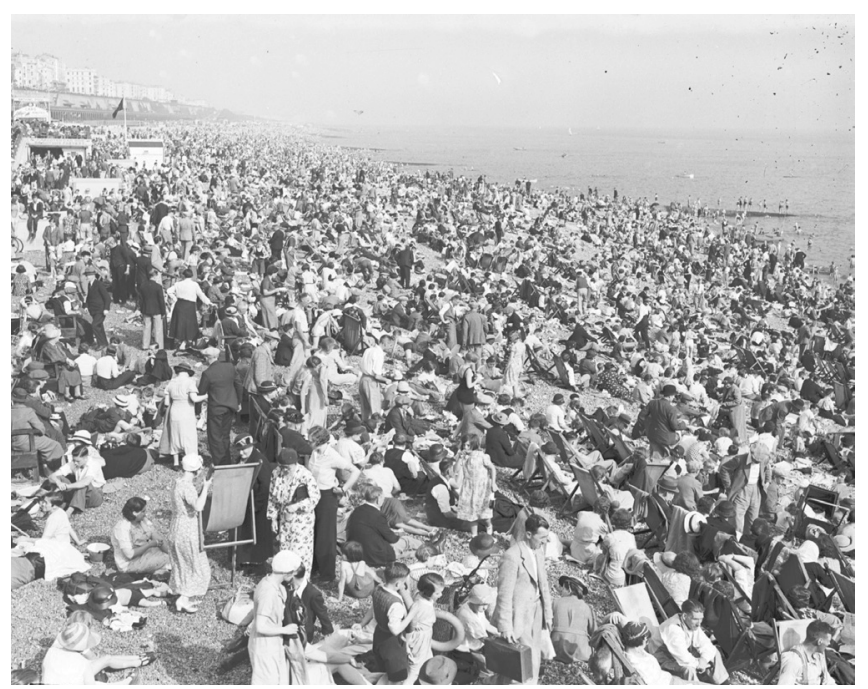

Figure 3: Brighton Beach circa 1930. Source: Royal Pavilion and Museums Brighton and Hove.

However, the first specimen of the so-called 'tourist', could not come into scene until the democratization of the right to rest. The regulation of the payed holidays was determinant for the transformation of the beach as a leisure space, usually overpopulated, where the crowd shows its two faces: the singularity of the individual and the generic-ness of the anonymous. Each figure is unique in his or her banality.

\section{THE BODY}

The beach as a social ritual is a place made up of bodies. The apparent randomness that organizes them along space produces a self-organized order mostly ruled by visibility and exposure, where nude bodies are stripped of social identification. ${ }^{4}$

This is why the beach is also a contested space where class conflict disappears while gender issues come to the fore. Apart from the evolution of the dress codes for swimsuits, which simply follows the general tendency towards smaller clothes and greater skin exposure, we can also find that, from the very beginning, the search for privacy produced various devices with different grades of autonomy than ranged from 'bathing machines' - four-wheeled carriages that were plunged into the water with their doors facing the sea - to portable 'skreenettes' - that stand in a midpoint between a foldable tent and an oversized dress.

Promiscuity and revelation of intimacy inherently belong to the beach. The way in which morality demands concealment or tolerates exposure is in direct relation to the social conventions at each time. But, of course, society only poses itself this type of questions on the grounds of women bodies. Still today.

Although rituals of disrobing in public have a long tradition that can be traced back to ancient thermal baths, separation between men and women was the general policy ${ }^{5}$. The current coexistence of both genders in the public space of the 


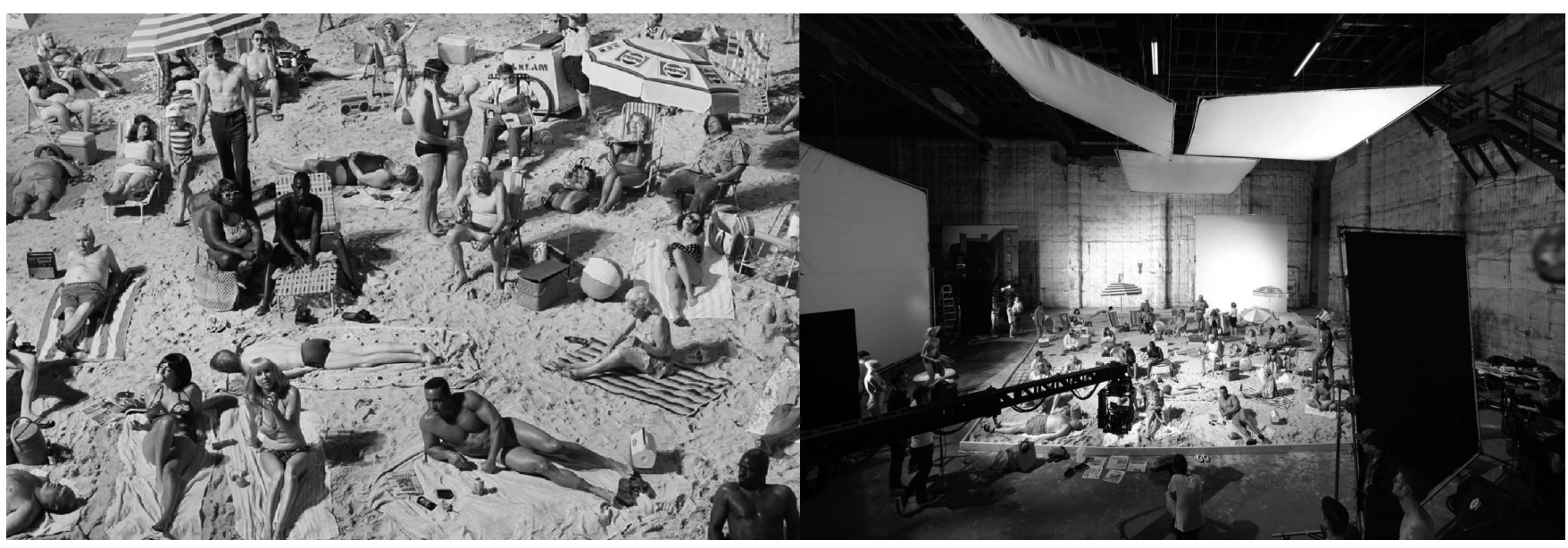

Figure 4: a) Alex Prager. Face in the Crowd. Crowd \#3, Pelican Beach, 2013. Source: www.alexprager.com. b) On set during the shooting of Alex Prager's Face in the Crowd. Foto: Mike Windle. Source: www.thecut.com

beach constitutes a suitable milieu to test the political agency of bodies. However, the influence of cultivation of self-image and the obsession with fitness and good shape cannot be underestimated as cultural inputs in the beach atmosphere.

\section{AUTHENTICITY}

But sometimes, an apparently natural behavior might be nothing more than 'staged authenticity'. This term, coined by the American sociologist Dean MacCannell ${ }^{6}$, originally referred to certain experiences designed to satisfy the tourist's fascination with 'real life', their desire to enter what Erving Goffman described as 'back regions'. However, a completely opposite tendency could also be identified: that is, the rehearsal of an ideal state of happiness through the arrangement of a touristic like set, just in the middle of what is supposed to be the ordinariness of city life. In this sense, the phenomena of urban beaches can exemplify the pursuit of such a goal: the experience of being a tourist in your own city.

In 2002, the city of Paris started a project called Paris-Plages. The first artificial beach had a length of $3 \mathrm{~km}$ starting in the proximities of the Louvre. Truckloads of sand were brought in, along with deck chairs and ice-cream vendors. Today, it has developed at several spots along the river banks of the Seine and has turned into a four-week-long event that provides the opportunity to lounge just as one of many other public urban services.

This fashion of sanded environments at the heart of the cityscape has spread along many other locations crossed by a river, such as the Spree in Berlin or the Arno in Florence, but also many others have popped-up in piazzas with no contact with water at all. This is the case of Detroit's Campus Marcius or London's Candem and Nothingham facilities. But unlike in Paris, these latest examples cannot be separated from their commercial exploitation as they are ruled by private interests and directly linked to the consumption of food or drink.

\section{CONCLUSION}

As we have seen, the singular contrast between the openness of the beach space and the intimacy of the domestic attitudes (lay, read, eat, sleep, chat, play, rest) that usually take place there, creates a unique sense of shared open-air interior. This is indeed the scope of these urban interventions that have tried to artificially reproduce what could be called the beach-effect.

But public space is not only defined by its physical qualities but by its predominant relational form. The beach-effect cannot be achieved by transportation of tons of sand and some colorful 'atrezzo'. If we think of public space as a place where both social cooperation and social conflict can be acted out, the famous claim to discover the beach under the pavement cannot turn out to be just a quest to put the beach 'on top'.

This naïve approach should be overcome and face the fact that intervening into public space is more than nothing, an affective endeavor. Neither urban planning nor architecture can dictate a single use of a given space. We can only provide a set of affordances, a space ready to be appropriated in a number of unforeseen ways.

In the context of an increasing tendency to address urban issues from an experiential standpoint, the beach can provide a model of new civility, understood as the capacity to relate positively to strangers.

\section{ENDNOTES}

1. Deleuze, Gilles, and Félix Guattari. Mille Plateaux: Capitalisme Et Schizophrénie. Tome 2. (Paris: Éditions de Minuit, 1980). English translation: A Thousand Plateaus: Capitalism and Schizophrenia. (London: Continuum, 2008) 530.

2. Corbin Alain. The Lure of the Sea: The Discovery of the Seaside in the Western World, 1750-1840. (Berkeley: University of California Press, 1994) 164.

3. Balzac, Honoré de. Un drame au bord de la mer. (Paris: De Vigny, 1843)

4. "The beach is a sort of microcosm where humanity is concentrated. It is a fantastic place to observe and document individuals because here people are themselves, do not act and get together regardless of the social class 


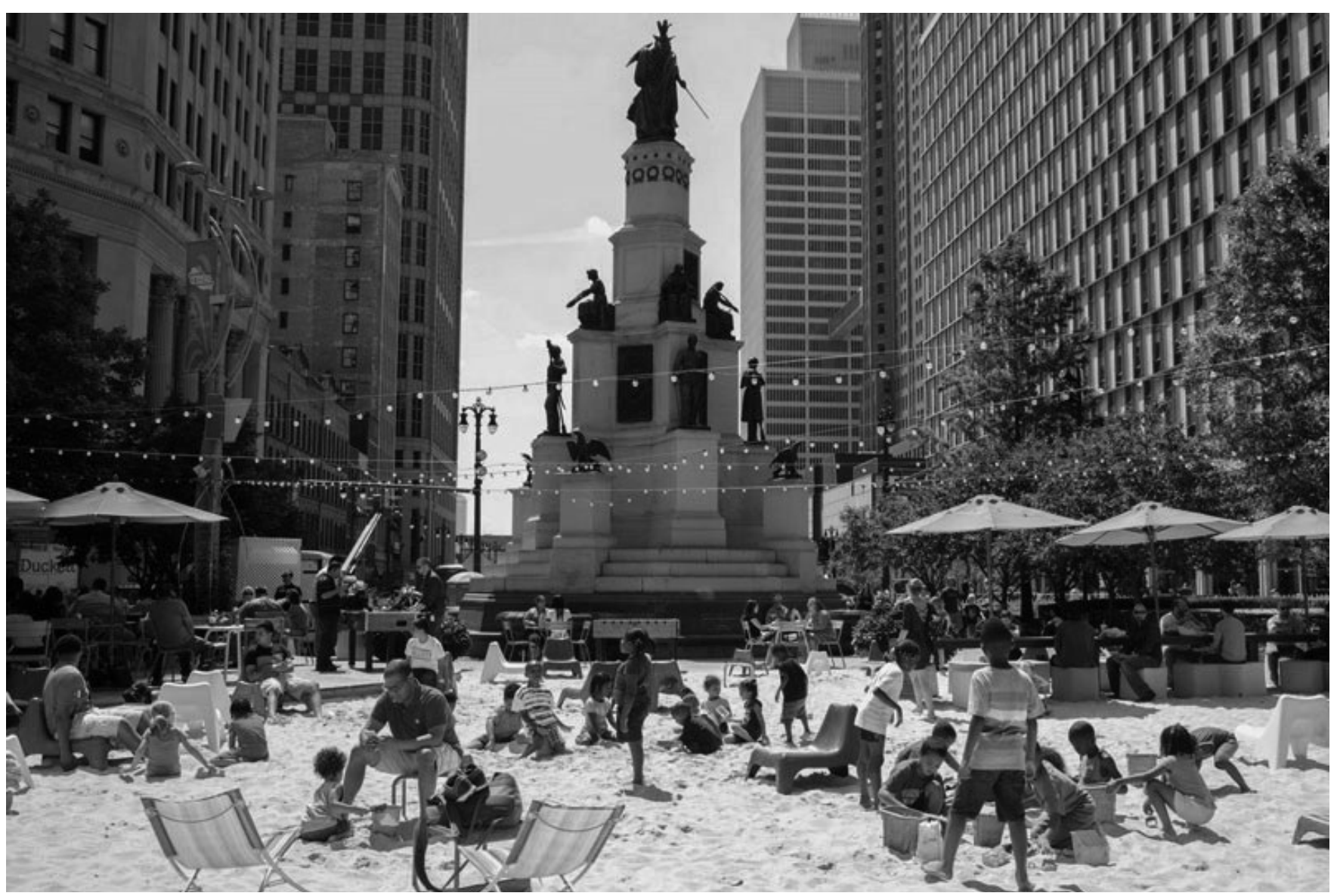

Figure 5: Detroit urban beach at Campus Martius featuring IKEA's new 2017 outdoor furniture collection. Source: www.clickondetroit.com

they belong to." "La spiaggia è una sorta di microcosmo dove si concentra

tutta l'umanità. Ė un luogo fantastico per osservare e documentare gli

persone di diversa estrazione." Massimo Vitali. https://www.huffingtonpost.

it/2016/08/07/massimo-vitali- fotografo- $\mathrm{n}$-11371308.html

5. For further analysis of the rituals of disrobing in public see: Watson, Sophie. City Publics: The (dis)enchantments of urban encounters (London: Routledge, 2006) chapter 5. p.80-110.

6. MacCannell, Dean. The Tourist: A New Theory of the Leisure Class (London: Macmillan, 1973). 